\title{
Gender and Conflict
}

\author{
Joshua Okyere ${ }^{1}$ \\ 'International Studies Dept, Ohio University, USA \\ Email:j0517016@ohio.edu
}

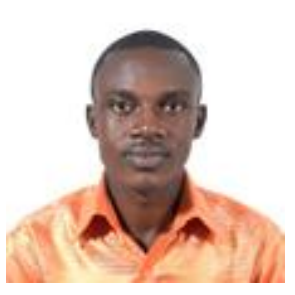

\begin{abstract}
Violent conflicts come with a high level of wreckage on lives, property, and survival networks. Armed conflict terrorizes and kills large numbers of people, creates economic dislocation, human and capital flight, massive impoverishment and social breakdown. Thus, making the challenges faced by post-conflict countries more severe than those faced by poor but peaceful developing countries. During a war, women are considered vulnerable to exploitation, abuse, sexual slavery, disease, and forced recruitment into armed groups. As survivors of violent conflict, they bear the burden of reconstruction. This kind of stereotypical connotation associated with women has led to gender inequality regarding who is considered as weak and victim during a war. It is contended that men are the ones who engage in war and when they are killed, disappear, or dislocated, women are left behind with the burden of ensuring family livelihood. Women and their roles in society have become more and more prominent not only in the scientific discussions of conflict but also post-conflict reconstruction and sustenance of peace. This work, therefore, sought to discuss how the discourse about war is gendered and throwed light on gendered violence in contemporary warfare and the gendered role played during war/conflict. Besides, it discusses the impact of conflict on women as well as the role women played in post-conflict reconstruction to enhance development. I do not try to base my arguments on a bias male perspective but the available literature and contend that though women suffer violence in war-torn societies, they are not only victims of war but also engage in war.
\end{abstract}

Keywords: Conflict, Gender

Citation | Joshua Okyere (2018). Gender and Conflict. Asian Journal of Social Sciences and Management Studies, 5(3): 82-86.

\section{History:}

Received: 2 April 2018

Revised: 18 April 2018

Accepted: 20 April 2018

Published: 23 April 2018

Licensed: This work is licensed under a Creative Commons

Attribution 3.0 License (cc) Er

Publisher:Asian Online Journal Publishing Group
Funding: This study received no specific financial support.

Competing Interests: The author declares that there are no conflicts of interests regarding the publication of this paper.

Transparency: The author confirms that the manuscript is an honest, accurate, and transparent account of the study was reported; that no vital features of the study have been omitted; and that any discrepancies from the study as planned have been explained.

Ethical: This study follows all ethical practices during writing.

\section{Contents}

1. Introduction

2. The Gendered Dimension of Conflict

3. Role of Gender and Women's Right in Post-Conflict Reconstruction ......................................................................... 84

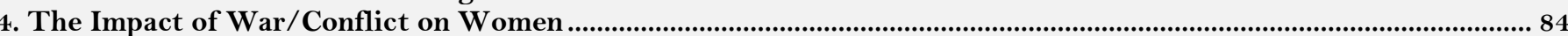

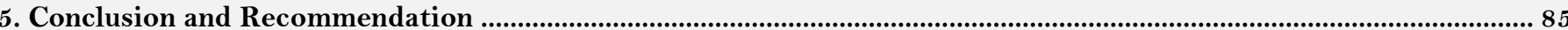

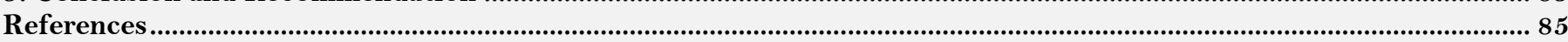




\section{Introduction}

Violent conflicts have been a permeating factor in today's world principally in less developed countries which has a lot of negative ramifications on development (Buvinic et al., 2012). Women are believed to be prone to exploitation and abuse ranging from sexual slavery, compulsory recruitment into armed groups during wartimes. As survivors of violent conflict, they bear the burden of reconstruction. This kind of stereotypical connotation associated with women has led to gender inequality regarding who is considered as weak and victim during a war. It is contended that men are the ones who engage in war and when they are killed, disappear, or dislocated, women are left behind with the burden of ensuring family livelihood.

Conflict from the social point of view refers to the struggles between two parties over scarce resources and goals that are not compatible. In the same vein, from the political perspective, conflict may be seen as intensified struggle at any level among groups who have the aim of gaining influence in areas of "power, resources, interest, needs" and to a certain degree, one of the group presupposes that there is incompatibility in that dimension of relationship (Igbuzor, 2011). Conflict does not always mean violence. However, the use of conflict in this work denotes violent conflicts and wars. Gender may simply be referred to the duties of men and women that are constructed by society and culture. The idea of gender also incorporates the desires held about the attributes, capabilities and possible practices of men and women herein referred to as masculinity and femininity (UNESCO, 2003 as cited in Unterhalter and North (2010)). Women have different perceptions with regards to the emanation of certain conflicts, the ways to handle it and the prospects available to prevent its intensification specifically due to the patriarchal nature of the society that has virtually excluded women from the "ownership and control of contested resources" (Sikoska and Solomon, 2002). Women are often excluded from the policy-making process in post-conflict situations. In spite of their salient role as peace builders, the unequal gender relations and male hegemony catalyze marginalization. Women and their roles in society have become more and more prominent not only in the scientific discussions of conflict but also post-conflict reconstruction and sustenance of peace (Birgitten, 1998; McGrew et al., 2004).

To do an analysis of the roots of conflict and how it can be prevented from a gendered standpoint, it will be prudent to examine the following questions.

How is the discourse of war gendered and what are the roles women play in war? What is the role of gender in post-conflict reconstruction? What are some of the gender roles and rights of women in a post-conflict environment?

What impact does war/conflict have on women?

\section{The Gendered Dimension of Conflict}

Wars and revolutions have been viewed as an exclusive preserve of men battling to either defend some class of people or champion the protection of State or a group's ideology. In these specific situations, women are characterized in their capacity as wives, mothers and considered vulnerable. "It is too simplistic to assume that it is in the nature of men and women to be situated in the public and private arenas, respectively, and that it is essence of their beings that men become associated with wars, revolutions, and rebellions, while women become associated with peace" (Afshar, 2003). This claim of society considering men to be assertive and hence the proponents of violent conflict call for the statement above. It would be blatant to conclude that all the time women are those who suffer during war. The gendered conception of the role women plays in "armed conflicts and wars" creates discrimination which reinforces the inequalities "between men and women" (Mjaaland, 2006). Most scholars consider women as victims, looking at the way women who are engaged in insurgent groups are sometimes coerced and forced to enroll, and also due to the widespread of sexual abuse during wartime (Coulter, 2008).

Empirical history of Middle East in an Islamic context debunks the notion of women regarded as peacemakers and emphasize on women as both revolutionaries and combatants (Afshar, 2003). For instance, Muslim women have kept on taking part in wars and battles over the century. Citing Iran as a case, Afshar (2003) notes that historically speaking, women have taken part in protest, rebellions, and revolutions in the form of leading riots to demand cheaper bread in the nineteenth century, played a more significant role in the tobacco revolution of 1981 which resulted in a ban on tobacco. In a similar vein, women in Iran during the second world war were active in the revolutions that took place in 1953 and 1979 (p.179). Women taking part in war is not a new phenomenon though the likelihood of it been accepted as a fact is minimal (Coulter, 2008).

Coulter (2008) argues that women are also active participants in war who serve in various capacities ranging from spies, soldiers, and rebels. However, she notes that there is a restriction concerning choices women make during conflict due to the hierarchical structures and context. She believed that war is still triggered by men and not women, but one cannot focus on women only as victims. Through a data demonstration gathered from interviews granted with some informants who had been both perpetrators and victims of the Sierra Leone war, he posits that majority of the women have had multiple experiences of either being a fighter, rape victims, looters, mothers or lovers. (p.69)

She provides an option for the dualism that sees men as violent perpetrators of war and women as active peacemakers. Coulter blames this kind of duality on the presence of humanitarian discourse by referring to Martha Thompson; 2006 who noted that "In most aid discourse and conflict analysis on women and war, women are 'located' primarily as refugees, displaced persons, or victims" (Thompson, 2006). He further noted that this notion of victimhood has crippled women and as a result has led to what he called 'lack of agency (Coulter, 2008).

Generally, women participate in wars that engulf their nations by either providing pragmatic support to the warriors or getting involved in the battlefield and fighting alongside with men. Women, for instance, were given the same military training as men in the ANC forces in South Africa to fight during the apartheid era and in Vietnam and Southern Sudan women were mighty warriors (Afshar, 2003).

Adel Halim, 1998 cited in Afshar (2003) notes that during wartime, there is a dilution of a gender barrier. This is to say because women act as active participants of war it helps do away with gender differences. It is, however, acknowledged that these bridging of gender differences might sometimes not live to see the test of time as men feel women participation are just marginal which further pushes for a relegation of women to the background. Women 
who do not have confrontations in the battlefield provide support to the men. In the wake of the Palestinian conflict, women played invisible roles publicly by sneaking food, keeping watch and sometimes created routes of escape for the men (Taylor, 1999 cited in Afshar (2003)).

Some scholars argue that violence perpetrated against civilians cannot be avoided neither is it a lousy ramification of war, but a significant strategy employed in contemporary wars (Mazurana, 2005 as cited in Thompson (2006)). This argument calls for a gendered examination of how warriors and those engaged in war see sexual violence as part of their approach and tactics. This point raises the question of always seeing masculine to be involved in military affairs while women remain victims.

\section{Role of Gender and Women's Right in Post-Conflict Reconstruction}

Post Conflict reconstruction is seen as dealing with the aftermath traumas of both civil wars and internal conflict in such countries to enhance the economic, political and social changes to provide a means to ensure peace and the promotion of democracy (Del Castillo, 2001). Post-struggle rehabilitation offers chances to set up new standards and guidelines, connect with new pioneers, and manufacture new organizations. Each of these procedures provides an opportunity to concentrate on women's rights, incorporating them in decision making and recognize and esteem them in the society (Zuckerman and Greenberg, 2004). There is a redefinition of national security ideas with regards to enhancing the "political and social status quo" which is entrenched in a factual and typical manner to bringing together "gender identities, roles and bodies in the service of the new polity" (Afshar, 2003).

Many at times, women have not been allowed to take an active part in the post-conflict reconstruction process. There is the situation that those who serve to mediate peace among the parties involved in war happen to be those who set the power relations for post-war activities (Al-Ali, 2005). During post-conflict reconstruction, the power to participate in politics is endowed to men while relegating women to the family and household duties (Cockburn and Zarkov, 2002). Some women in war-torn societies, however, find ways and means to champion the cause of peace and reconciliation by engaging in grassroots advocacy (Al-Ali, 2005). For instance, during the post-conflict reconstruction in Northern in Sri Lanka, women played a pivotal role in the peace process and hence debunked the notion that they are not present or not adequately represented in the post-conflict process. During policy, women views are heard and incorporated into all aspect of peace and reconciliation process (Harris, 2004). The continuous marginalization of women in post-conflict environment necessitated a call for a UN resolution geared towards gender mainstreaming in 2000. A UN resolution adopted in 2000 by the security council calls on all member countries in their quest to maintain peace and security to include women as well as increase their role in making decisions in areas of "conflict prevention and resolution" (Mjaaland, 2006).

Also, Women's role as caretakers of home traditionally necessitates in a post-conflict environment their role of emotional adjustment. Since ideologies are only halted during wars, after wars, the revival of the nation has ideologically become dependent on women. They return to their homes to partake in their usual household chores of caring for the home. However, in most cases due to the ravaging effects of conflict such as racial identity may serve as a barrier to women in maintaining their place in society to perform their functions as socializers in their families (Afshar, 2003). As stated earlier, there is the need for women's right to be considered during post-conflict reconstruction to enhance gender equality.

Zuckerman and Greenberg (2004) noted that there are four main set of rights which needs to be tackled from the lens of Women-in-development approach to help eliminate gender inequality. Notable among them are rights to political participation of women in the form of drafting constitutions and filling positions that were hitherto occupied by men. They argue that there is the need to reinforce women skill for leadership by spending resources to develop women's ability to contest for a position, win seats and serve effectively and efficiently. By this, women would be able to bring social transformation and promote gender equality in their governance. Also, right to own property. During post-conflict reconstruction, there is dispute resolution and the drafting of property laws to safeguard the rights of individuals to property ownership. These laws drafted must be geared towards giving women the authority to own property.

Again, women have the right to be employed. Post-conflict reconstruction usually comes with new laws eliminating gender inequality, however, if there is no vigorous enforcement of the laws, employers often ignore the law and discriminate. There is, therefore, a need for strict enforcement of laws to eradicate discrimination in employment to enhance gender equality.

Additionally, women in a post-conflict environment are entitled to the enjoyment of the right to freedom from violence. It is believed that the demobilized soldiers having been exposed to military life are likely to use force to inflict pains and abuse on women, and hence women need to be protected to enhance equitable gender relations.

\section{The Impact of War/Conflict on Women}

Women are adversely affected than men in wartime. Women suffer from the consequences of war that are indirect (Plümper and Neumayer, 2006). There is the general contention that women become displaced economically in times of conflict with regards to their roles both in the home and in the community. According to Justino et al. (2012) there is not enough evidence or proof to support that contention. However they note that there are some recent comparative case studies that have been conducted in countries like Tajikistan and Timor-Leste, Kosovo, Bosnia and Herzegovina etc that goes on to attest to the fact that conflict can serve as a means of increasing the economic activity of women primarily through partaking in the labor market which he believes will most often lead to an enhancement in the welfare of both the home and society (Justino et al., 2012). Though conflict may serve as a means of increasing women economic activity, it has become a rule that in many cases female work is associated with reduced remuneration, low-skilled jobs. Etc. In the same vein, El-Bushra and Sahl (2005) basing their arguments on case studies from Uganda, Sudan, Mali, Angola and Somalia which are the conflict-prone zones in Africa posit that women gain greater economic participation which enhances their empowerment in the home. According to them in many cases, women are empowered to be decision makers within the family once they become the main providers of needed items for survival. They, however, discovered that, though there may be changes in social, institutional practices in conflict situations but is generally to a limited 
degree. We can see from this that even if women assume the role of a breadwinner, it would just be for a while and they would return to their state of nature.

Ruddick et al. (1998) argued that women went through many atrocities ranging from death, sexual abuse and anguish, losing their precious ones, homes, and communities. There is the assumption that women are not likely to die during wartimes since generally speaking, there are few women who serve in the armed forces. But there is a high propensity of civilian women being killed in war than soldiers (Ruddick et al., 1998). In addition, they contended that women are direct casualties of war. This is because the bombings that are released target civilians and according to the history of the past centuries, more civilians are killed. Women who do not die are susceptible to be refugees as they become displaced. To them, about four out five women in addition to their plight suffer sexual abuse, forced prostitution, rape and the likes (Ruddick et al., 1998). When gendered violence perpetrated in society is supported and sanctioned by 'structural violence,' women security would no more exist (Mjaaland, 2006). This demonstrates that the safety of women is at stake in times of conflict. During wartime, women are coerced into marriages. They become vulnerable and are most at times compelled to marry their comrades as they fight alongside. They are also subjected to sexual abuses (Afshar, 2003). Women experience the ill effects of the conflict which leads to adverse health, economic impoverishment, infrastructural devastation and as well suffers displacement and dislocation in times of the war and its aftermath. The social order is broken, and the adverse effect is serving as a catalyst for males to behave aggressively against women, who are in most cases subjected to sexual savagery both inside and outside their local family units (Plümper and Neumayer, 2006).

Women suffer a severe physical insecurity throughout wars which places them in a state of terror. When there is a cease of fire, the combatants and warriors who are not employed continue to pose a threat to the life of the innocent people which eventually makes women trapped in their homes preventing them from going on with their social and economic activities (Kumar, 2000). In spite of the insecurity, the economic responsibilities of women in the face of poverty and hardship are heightened during and after conflict. In a case study conducted in Bosnia, women continued to "perform their tasks such as cooking, washing clothes and caring for children despite their spending more hours on farm work or other jobs" (Kumar, 2000). Again, women are subjected to domestic violence by men in countries affected by war. It is believed that violence creates a "subculture of violence." This is to say a culture that sees acts of violence/ violent behavior as normal (Kumar, 2000).

\section{Conclusion and Recommendation}

I have demonstrated that women are vulnerable to the ravaging effects of war. As a result of this women have been labeled as victims of war. However, the literature makes it clear that though women experience severe effects of war, they also go to war and perform specific great roles to enhance peace as well. It is interesting to note that in spite of the UN resolution of 1325 geared towards women inclusion and gender mainstreaming, the realities of the aftermath of conflict is relatively different. In some post-conflict situations, there is the belief that this UN resolution is an attempt of the western imperialist to destroy traditional values and culture of society.

There is the need to take into consideration the role women play as peacemakers while digesting the myth surrounding women's non-involvement in violent conflicts. In spite of the fact that women around the world have alternate point of view with regards to war, it can be contended that a large number of them share a solid sense of duty regarding peace and sustenance and this, in turn, empowers them to survive war which does not have any definite bearing on their lives (Afshar, 2003).

I believe that to enhance a breakthrough of gender equality and the acknowledgments of the rights of women in a post-conflict environment; there have to be incentives for men. Placing only women at the center in the quest to implementing UNSCR 1325 will not lead to a full solution of the problem. It would be like killing a snake without cutting the head. The man who is already championing the course of gender equality should be motivated to carry on their excellent work.

There is also the need for the provision of education for both mediators and negotiators of conflict. Both male and females need to be educated to know how to include gender-sensitive issues in peace talks and post-conflict reconstruction.

\section{References}

Afshar, H., 2003. Women and wars: Some trajectories towards a feminist peace. Development in Practice, 13(2/3): 178-188. View at Google Scholar $\mid$ View at Publisher

Al-Ali, N., 2005. Reconstructing gender: Iraqi women between dictatorship, war, sanctions and occupation. Third World Quarterly, 26(4/5): 739-758. View at Google Scholar $\mid$ View at Publisher

Birgitten, S., 1998. Women and post-conflict reconstructions: Issues and sources. War-Thorn Society project. Occasional Paper No. 3.

Buvinic, M., M. Das Gupta, U. Casabonne and P. Verwimp, 2012. Violent conflict and gender inequality: An overview. World Bank Research Observer, 28(1): 110-138. View at Google Scholar $\mid$ View at Publisher

Cockburn, C. and D. Zarkov, 2002. The postwar moment: Militaries, masculinities and international peacekeeping. London: Lawrence \& Wishart.

Coulter, C., 2008. Female fighters in the Sierra Leone war: Challenging the assumptions? Feminist Review, 88(1): 54-73. View at Google Scholar View at Publisher

Del Castillo, G., 2001. Post-conflict reconstruction and the challenge to international organizations: The case of El Salvador. World Development, 29(12): 1967-1985. View at Google Scholar $\mid$ View at Publisher

El-Bushra, J. and I. Sahl, 2005. Cycles of violence: Gender relations and armed conflict. Nairobi: ACCORD.

Harris, S., 2004. Gender, participation, and post-conflict planning in Northern Sri Lanka. Gender and Development, 12(3): 60-69. View at Google Scholar | View at Publisher

Igbuzor, O., 2011. Peace and security education: A critical factor for sustainable peace and national development. International Journal of Peace and Development Studies, 2(1): 1-7. View at Google Scholar

Justino, P., I. Cardona, R. Mitchell and C. Müller, 2012. Quantifying the impact of women's participation in post-conflict economic recovery (HiCN Working Paper No.131). Brighton: IDS.

Kumar, K., 2000. Women and women's organizations in postconflict societies: The role of international assistance. Center for Development Information and Evaluation, US Agency for International Development.

McGrew, L., K. Frieson, S. Chan and S.N. Anderlini, 2004. Good governance from the ground up: Women's roles in post-conflict Cambodia. Hunt Alternatives Fund.

Mjaaland, S., 2006. United Nations security council resolution 1325 on women, peace and security: How does women's groups and activist in Uganda engage in the implementation of UN SCR 1325 on women, peace and security? (Master's Thesis). 
Plümper, T. and E. Neumayer, 2006. The unequal burden of war: The effect of armed conflict on the gender gap in life expectancy. International Organization, 60(3): 723-754. View at Google Scholar $\mid$ View at Publisher

Ruddick, S., L.A. Lorentzen and J. Turpin, 1998. The women and war reader.

Sikoska, T. and J. Solomon, 2002. Introducing gender in conflict and conflict prevention: Conceptual and policy implications. Gedownload, 20 .

Thompson, M., 2006. Women, gender, and conflict: Making the connections. Development in Practice, 16(3-4): 342-353. View at Google Scholar 1 View at Publisher

Unterhalter, E. and A. North, 2010. Assessing gender mainstreaming in the education sector: Depoliticised technique or a step towards women's rights and gender equality?

Zuckerman, E. and M. Greenberg, 2004. The gender dimensions of post-conflict reconstruction: An analytical framework for policymakers. Gender \& Development, 12(3): 70-82. View at Google Scholar $\mid$ View at Publisher 